\title{
Avaliação da eficiência do uso da energia elétrica no Perímetro Irrigado de Pirapora, $\mathrm{MG}^{1}$
}

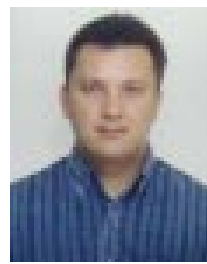

Salomão de S. Medeiros², Antônio A. Soares ${ }^{3}$, Márcio M. Ramos ${ }^{4}$, Everardo C. Mantovani ${ }^{5}$ \& José A. A. de Souza ${ }^{6}$

\begin{abstract}
${ }^{1}$ Parte da dissertação apresentada à UFV pelo primeiro autor, para obtenção do título de Mestre em Engenharia Agrícola ${ }^{2}$ DEA/UFV. Av. Santa Rita 110, apt. 401, Centro, CEP 36570-000, Viçosa, MG. Fone: (31) 3891 6791. E-mail: salommao@zipmail.com.br (Foto) ${ }^{3}$ DEA/UFV. Av Ph. Rolfs s/n, CEP 36570-000, Viçosa, MG. E-mail: aasoares@mail.ufv.br

${ }^{4}$ DEA/UFV. E-mail: mmramos@mail.ufv.br

${ }^{5}$ DEA/UFV. E-mail: everaldo@mail.ufv.br

${ }^{6}$ DEA/UFV. E-mail: jalbertoalves@vicosa.ufv.br
\end{abstract}

Protocolo $63-7 / 5 / 2002$ - Aprovado em 13/5/2003

\begin{abstract}
Resumo: Objetivou-se, através deste trabalho, avaliar a eficiência de uso de energia elétrica no Perímetro Irrigado de Pirapora, no período de 1999 a 2000. A demanda anual de água de irrigação para o perímetro foi simulada com base no balanço de água no solo, para condições de um manejo de irrigação ideal. O índice médio anual de consumo de energia no perímetro foi determinado com base no volume de água aplicado e no consumo de energia das estações de bombeamento. Com o volume de água simulado e o índice médio anual de consumo de energia, estimou-se o consumo de energia necessário para a condição de manejo de irrigação ideal. 0 consumo de energia estimado foi comparado com o consumo real, permitindo concluir-se que: em razão da aplicação excessiva de água, o consumo de energia elétrica também foi excessivo; portanto, é imprescindível a implantação de um programa de manejo de irrigação visando otimizar o uso de água e de energia elétrica.
\end{abstract}

Palavras-chave: energia elétrica, eficiência, perímetro

\section{Assessment of efficiency of electrical energy use in the Pirapora Irrigation District, MG, Brazil}

\begin{abstract}
The efficiency of electrical energy use was evaluated in the Pirapora Irrigation District, during the years of 1999 and 2000. The irrigation demand was simulated based on the soil water balance, considering an optimum irrigation management. The annual average energy consumption index for the irrigation district was determined using the water irrigation volume applied and the energy consumption in the pumping plants. With the simulated water volumes and the mean annual energy consumption index, the energy consumption was simulated for the condition of an ideal irrigation management. The simulated energy consumption was compared with the real one. According to the results it may be concluded that due to excessive water application the energy consumption was high. Thus, a good irrigation management program is needed to optimize the use of water and electrical energy in the Pirapora Irrigation District.
\end{abstract}

Key words: electrical energy, efficiency, irrigation district

\section{INTRODUÇÃO}

A energia elétrica é, sem sombra de dúvidas, um insumo importantíssimo para o desenvolvimento das civilizações modernas, estando presente em quase todas as atividades do processo produtivo.

A trajetória brasileira do setor elétrico decorre de iniciativas realizadas a partir de meados do século XIX, para substituir o carvão mineral importado, que era fonte básica de energia para transporte, indústria e iluminação. Dom Pedro II, bastante interessado nos avanços científicos de sua época, incentivou a adoção das novas tecnologias no campo da eletricidade. Em 1879 ele concedeu, a Thomas Edson, o direito de introduzir, no Brasil, processos e equipamentos para a geração de eletricidade. Naquele ano foi inaugurada a iluminação da estação ferroviária Central do Brasil, na época Estrada de Ferro D. Pedro II, no Rio de Janeiro.

Entre 1879 e 1890, várias usinas de pequeno porte foram instaladas para a geração de energia elétrica, como as de Ribeirão do Inferno (1883) e Marmelos (1889) ambas em Minas Gerais. No período entre 1890 e 1900, foram instaladas dez outras pequenas usinas, com capacidade para geração de $1.200 \mathrm{KW}$. 
Na virada do século XIX para o século XX, o potencial de desenvolvimento das cidades do Rio de Janeiro e São Paulo atraiu o capital estrangeiro para a instalação de companhias de energia elétrica no Brasil, desenvolvendo a vocação hidrelétrica brasileira.

O Brasil tem a maior disponibilidade hídrica superficial do mundo, com um incomparável potencial de geração hidroelétrica. Daí, a natural e histórica opção dos brasileiros por esta matriz energética. As usinas hidroelétricas proliferaram a partir da década de 50, dando sustentação ao forte impulso do País rumo à industrialização e ao desenvolvimento. Hoje, o País dispõe de um dos maiores parques hidrelétricos do mundo, respondendo por quase $90 \%$ do total da energia gerada.

O sistema elétrico brasileiro foi planejado a partir de uma das piores secas ocorridas no século passado, entre os anos de 1951 e 1956. Para fazer face à eventualidade de um novo episódio como este, o sistema foi concebido de modo a funcionar a plena carga, com a ocorrência de longos ciclos de escassez de chuvas, o que é possível com a manutenção de excedentes armazenados em grandes reservatórios. Levandose em conta os diferentes regimes pluviométricos característicos das diversas regiões brasileiras, instalou-se também, progressivamente, uma rede de transmissão interligada, que permite o pleno atendimento do setor, mesmo em regiões onde eventualmente haja escassez de água e energia.

Por muitos anos, o Brasil conviveu com a impressão de que suas fontes hidroenergéticas eram inesgotáveis. De fato, teoricamente, seria ainda possível dobrar, em alguns anos, o número de hidrelétricas instaladas no País, sem provocar danos irreversíveis ao meio ambiente. No entanto, a população brasileira mais do que triplicou nos últimos 40 anos, e esta, de uma ocupação predominantemente agrária e rural, se inverteu para urbana e industrial. A demanda por energia elétrica cresceu naturalmente, de forma exponencial, até que, em meados dos anos 90, o sistema hidrelétrico instalado começou a dar sinais de esgotamento. Os excedentes de água, que davam garantia de abastecimento por cinco anos, passaram a ser utilizados acima da taxa de recomposição natural durante os períodos chuvosos. Ainda em 2001, o Brasil foi submetido a um dos piores regimes pluviométricos das últimas décadas que, aliado à falta de investimentos no setor energético, culminou na maior crise energética já existente.

Com base no art. 62 da Constituição Federal, o Presidente da República promulgou a Medida Provisória nº 2.198-5, de 24 de agosto de 2001, criando e instalando a Câmara de Gestão da Crise de Energia Elétrica - GCE, com o objetivo de propor e implementar medidas de natureza emergencial, decorrentes da atual situação hidrológica crítica, para compatibilizar a demanda e a oferta de energia elétrica, de forma a evitar interrupções intempestivas ou imprevistas do suprimento de energia elétrica. Diante da crise energética, influenciada pela escassez de água, agravada pela falta de investimentos no setor, objetivou-se, neste trabalho, avaliar o consumo de energia elétrica no Perímetro Irrigado de Pirapora, MG, durante os anos de 1999 e 2000, para a condição de um manejo de irrigação adequado, uma vez que a agricultura irrigada consome $7.789 \mathrm{GWh}^{-1} \mathrm{ano}^{-1}$, o que corresponde a $1,4 \%$ da capacidade instalada de geração hidroelétrica no Brasil (Lima et al., 2002).

\section{MATERIAL E MÉTODOS}

Este trabalho foi realizado no Perímetro Irrigado de Pirapora, MG, localizado a $12 \mathrm{~km}$ da cidade de Pirapora, nas margens da BR 365, rodovia que liga o norte de Minas Gerais ao Triângulo Mineiro e Distrito Federal, cujas coordenadas geográficas são $17^{\circ} 21^{\prime}$ de latitude Sul, 44 56' de longitude Oeste e 489 m de altitude. Este perímetro apresenta uma área de 1.683 ha, sendo 1.236 irrigáveis, 163 de agricultura de sequeiro, 243 de reserva permanente e 41 ha de infra-estrutura. Durante os anos de 1999 e 2000 o perímetro apresentava uma área efetivamente irrigada de 450 e 532 ha, respectivamente.

A infraestrutura de irrigação do perímetro é composta de duas estações de bombeamento, em que a primeira, denominada captação, recalca água do Rio São Francisco para um reservatório com capacidade de $32.500 \mathrm{~m}^{3}$, e a segunda, denominada booster, capta água do reservatório, e a distribui para todos os lotes, onde ela é recebida já pressurizada.

Para avaliação da eficiência do uso da energia elétrica foi estimado o volume de água necessário para as culturas, com base no balanço de água no solo, a partir dos elementos do clima, propriedades físicas do solo e estádios de desenvolvimento das culturas. Tal metodologia é descrita detalhadamente por Medeiros et al. (2003). Este volume foi comparado com o somatório dos volumes de água medidos nos hidrômetros de cada lote do perímetro, para determinar os volumes em excesso e em déficit no perímetro, de 1999 a 2000. Com as informações sobre o volume bombeado pelo sistema de captação e volume de água registrados nos hidrômetros, assim como as informações sobre as demandas registradas e os consumos de energia para as estações de bombeamento, determinaram-se os índices de demanda de potência $\left(\mathrm{kW} \mathrm{m}^{-3}\right)$ e de consumo de energia $\left(\mathrm{kWh} \mathrm{m}^{-3}\right)$. Tais índices permitem avaliar-se, durante o ano, os meses que obtiveram os melhores e piores rendimentos entre demanda registrada e volume bombeado e consumo de energia e volume bombeado, de forma que se possa realizar intervenções na forma de distribuição de água, a fim de se obter os melhores rendimentos.

O índice de demanda de potência mensal para a estação de bombeamento captação foi obtido pela razão da demanda de potência mensal registrada nesta estação de bombeamento e o volume mensal de água bombeado pela mesma, sendo que o volume foi estimado por meio da curva de rendimento da bomba. O índice de demanda de potência mensal, para a estação de bombeamento booster foi obtido por meio da razão entre a demanda de potência mensal registrada na referida estação de bombeamento e o somatório do volume mensal de água registrado nos hidrômetros; os índices de demanda de potência mensal para o perímetro foram obtidos por meio da razão entre o somatório das demandas de potência mensal registradas nas estações de bombeamento e o somatório do volume de água mensal registrado nos hidrômetros.

O índice de consumo de energia mensal, para a estação de bombeamento captação foi obtido por meio da razão entre o consumo de energia mensal, registrado na referida estação de bombeamento, e o volume mensal de água bombeado pela mesma. $\mathrm{O}$ índice de consumo de energia mensal, para a estação de bombeamento booster foi obtido por meio da razão 
entre o consumo de energia registrado na referida estação de bombeamento e o somatório do volume mensal de água registrados nos hidrômetros, enquanto o índice de consumo de energia mensal para todo perímetro o foi através da razão entre o somatório dos consumos mensais registrados nas estações de bombeamento e o somatório do volume de água mensal registrado nos hidrômetros.

A partir dos resultados obtidos dos índices mensais de consumo de energia para o perímetro, determinou-se o índice médio anual de consumo de energia no perímetro, nos anos de 1999 e 2000. Com os volumes de água simulados para o mesmo período e o índice médio anual de consumo de energia, estimouse o consumo de energia para a condição de manejo de irrigação adequado. Comparando-se o consumo de energia real e o consumo estimado, determinou-se também o excesso e o déficit de energia no perímetro de 1999 a 2000.

\section{RESULTADOS E DISCUSSÃO}

\section{Uso da água no perímetro}

Os volumes de água simulados, correspondentes aos anos de 1999 e 2000, para todo o perímetro, são apresentados na Tabela 1, bem como os volumes aplicados em excesso e em déficit. Os volumes de água simulados para todo o perímetro, correspondentes aos anos de 1999 e 2000 , foram de 4.555 .125 e $4.493 .838 \mathrm{~m}^{3}$, apresentando um consumo anual de água estimado de 10.116 e $8.451 \mathrm{~m}^{3} \mathrm{ha}^{-1}$ ano $^{-1}$. Observa-se a ocorrência de um decréscimo no consumo anual de água, para o perímetro, de $16 \%$. A redução no consumo anual de água foi ocasionada pela redução na demanda hídrica das culturas, ocorrida no ano de 2000 e influenciada pelo clima.

Os volumes aplicados em excesso no perímetro, para os anos de 1999 e 2000, foram de 4.537 .574 e $3.758 .274 \mathrm{~m}^{3}$, respectivamente, representando, em termos porcentuais, uma aplicação excessiva de 100 e 84\%. Apesar da aplicação excessiva de água verificada no perímetro, os meses de janeiro de 1999 e janeiro, fevereiro, março e abril de 2000 apresentaram déficits.

A ocorrência de déficits nos meses supra citados deve-se à interrupção parcial da prática de irrigação, justificada pelo fato de, nesses meses, predominar a estação chuvosa na região, que se concentra de outubro a março. No entanto, por se tratar de uma região onde há predomínio de irregularidade espaço- temporal das chuvas, estas não são aproveitadas de forma totalmente efetiva pelos cultivos e, associada a alta demanda atmosférica, leva à ocorrência de déficits hídricos nesses meses. Entretanto, o agricultor que não usa nenhuma técnica de manejo de irrigação acredita que as chuvas ocorridas são suficientes para a cultura e cessam as irrigações, provocando assim o déficit hídrico. Verifica-se, portanto, que devido a esse balanço hídrico negativo observado no perímetro, o manejo no uso da água não foi realizado de forma adequada para os anos de 1999 e 2000, uma vez que é baseado em experiência do produtor que, em reuniões semanais, solicita junto à gerência do perímetro, $\mathrm{o}$ volume de água supostamente necessário.

\section{Índices de demanda de potência}

Os índices de demanda de potência $\left(\mathrm{kW} \mathrm{m}^{-3}\right)$ e consumo de energia $\left(\mathrm{kWh} \mathrm{m}^{-3}\right)$ são apresentados nas Tabelas 2 e 3, respectivamente. Dentre as estações de bombeamento (captação e booster) a que apresentou maiores índices médios anuais de demanda de potência foi o booster, com valores de $0,0043 \mathrm{e}$ $0,0042 \mathrm{~kW} \mathrm{~m}^{-3}$, para os anos de 1999 e 2000 , respectivamente, caracterizando um baixo rendimento com relação à captação, embora o rendimento tenha aumentado em $2 \%$ durante o ano 2000.

Os índices de demanda de potência, para o perímetro, apresentaram valores médios anuais de 0,0056 e $0,0066 \mathrm{~kW} \mathrm{~m}^{-3}$, durante os anos de 1999 e 2000, respectivamente, havendo um decréscimo no rendimento anual de $18 \%$. Este decréscimo se justifica em razão da alta demanda registrada nas estações de bombeamento e do decréscimo de $11 \%$ no volume de água aplicado, pois o sistema era acionado para aplicar apenas parte do volume de água que é capaz de bombear.

Os meses de janeiro de 1999 e 2000 foram os que apresentaram os menores rendimentos mensais de demanda de potência, tanto para o booster $\left(0,0339\right.$ e $\left.0,0306 \mathrm{~kW} \mathrm{~m}^{-3}\right)$ quanto para a captação $\left(0,0425\right.$ e $\left.0,0515 \mathrm{~kW} \mathrm{~m}^{-3}\right)$. Esses baixos rendimentos são devidos à relação entre a alta demanda registrada e o pequeno volume de água aplicado nos lotes.

\section{Índices de consumo de energia}

Os índices médios anuais de consumo de energia foram maiores no sistema de bombeamento booster, com valores de 0,3140 e $0,3017 \mathrm{kWh} \mathrm{m}^{-3}$, nos anos de 1999 e 2000 , respectivamente, caracterizando um baixo rendimento com

Tabela 1. Volume de água aplicado e simulado, em excesso e em déficit, para o Perímetro Irrigado de Pirapora, MG, durante os anos de 1999 e 2000

\begin{tabular}{|c|c|c|c|c|c|c|c|c|c|c|c|c|c|}
\hline & \multicolumn{13}{|c|}{ Volume de Água $\left(10^{3} \mathrm{~m}^{3}\right)$} \\
\hline & Jan & Fev & Mar & Abr & Mai & Jun & Jul & Ago & Set & Out & Nov & Dez & Total \\
\hline \multicolumn{14}{|c|}{1999} \\
\hline Simulado & 318,7 & 290,8 & 277,2 & 463,4 & 501,9 & 459,9 & 507,1 & 585,3 & 578,5 & 365,2 & 52,0 & 155,1 & $4.555,1$ \\
\hline Excesso & 0,0 & 4,0 & 464,6 & 42,2 & 460,8 & 544,8 & 571,3 & 382,1 & 529,7 & 812,4 & 695,1 & 30,7 & $4.537,6$ \\
\hline Déficit & 295,1 & 0,0 & 0,0 & 0,0 & 0,0 & 0,0 & 0,0 & 0,0 & 0,0 & 0,0 & 0,0 & 0,0 & 295,1 \\
\hline Simulado & 254,1 & 290,4 & 375,2 & 466,3 & 494,3 & 456,0 & 412,5 & 476,8 & 462,5 & 425,7 & 192,5 & 187,4 & $4.493,8$ \\
\hline Excesso & 0,0 & 0,0 & 0,0 & 0,0 & 368,4 & 613,0 & 540,0 & 469,4 & 506,0 & 215,8 & 991,4 & 54,3 & $3.758,3$ \\
\hline Déficit & 245,5 & 61,1 & 73,5 & 3,6 & 0,0 & 0,0 & 0,0 & 0,0 & 0,0 & 0,0 & 0,0 & 0,0 & 383,7 \\
\hline
\end{tabular}


Tabela 2. Índices de demanda de potência durante os anos de 1999 e 2000

\begin{tabular}{|c|c|c|c|c|c|c|c|c|c|c|c|c|c|}
\hline \multirow{2}{*}{$\begin{array}{c}\text { Estação de } \\
\text { Bombeamento }\end{array}$} & \multicolumn{13}{|c|}{ Demanda de Potência $\left(\mathrm{kW} \mathrm{m}^{-3}\right)$} \\
\hline & Jan & $\mathrm{Fev}$ & Mar & Abr & Mai & Jun & Jul & Ago & Set & Out & Nov & Dez & Média \\
\hline \multicolumn{14}{|c|}{1999} \\
\hline Booster & 0,0339 & 0,0034 & 0,0013 & 0,0019 & 0,0010 & 0,0010 & 0,0009 & 0,0010 & 0,0009 & 0,0008 & 0,0013 & 0,0046 & 0,0043 \\
\hline Perímetro & 0,0425 & 0,0047 & 0,0018 & 0,0026 & 0,0014 & 0,0013 & 0,0012 & 0,0014 & 0,0012 & 0,0012 & 0,0018 & 0,0064 & 0,0056 \\
\hline \multicolumn{14}{|c|}{2000} \\
\hline Perímetro & 0,0515 & 0,0056 & 0,0041 & 0,0027 & 0,0014 & 0,0012 & 0,0014 & 0,0014 & 0,0014 & 0,0020 & 0,0013 & 0,0054 & 0,0066 \\
\hline
\end{tabular}

Tabela 3. Índices de demanda de energia durante os anos de 1999 e 2000

\begin{tabular}{|c|c|c|c|c|c|c|c|c|c|c|c|c|c|}
\hline \multirow{2}{*}{$\begin{array}{c}\text { Estação de } \\
\text { Bombeamento }\end{array}$} & \multicolumn{13}{|c|}{ Consumo de Energia $\left(\mathrm{kW} \mathrm{m}^{-3}\right)$} \\
\hline & Jan & Fev & Mar & Abr & Mai & Jun & Jul & Ago & Set & Out & Nov & Dez & Média \\
\hline & \multicolumn{13}{|c|}{1999} \\
\hline Captação & & 0,1551 & 0,1453 & & 0,1684 & 0,1327 & 0,3400 & & 0,0146 & & & & 0,1667 \\
\hline Booster & 0,3503 & 0,3177 & 0,3069 & 0,2364 & 0,3274 & 0,2613 & 0,3586 & 0,2937 & 0,3277 & 0,3017 & 0,3252 & 0,3605 & 0,3140 \\
\hline \multirow[t]{2}{*}{ Perímetro } & 0,6028 & 0,4673 & 0,4523 & 0,3492 & 0,4845 & 0,3958 & 0,7172 & 0,4395 & 0,3429 & 0,4480 & 0,4873 & 0,5414 & 0,4773 \\
\hline & \multicolumn{13}{|c|}{2000} \\
\hline Captação &, $28<0$ & 0,1467 & 0,0741 & & 0,1058 & 0,1765 & 0,1438 & & & & & & 0,1537 \\
\hline Booster & 0,1323 & 0,3219 & 0,1608 & 0,3483 & 0,2938 & 0,3256 & 0,3344 & 0,2960 & 0,3391 & 0,2918 & 0,3133 & 0,4636 & 0,3017 \\
\hline Perímetro & 0,4182 & 0,4837 & 0,2396 & 0,5215 & 0,4358 & 0,4850 & 0,5042 & 0,4451 & 0,5130 & 0,4369 & 0,4700 & 0,6881 & 0,4701 \\
\hline
\end{tabular}

relação à captação, embora o rendimento tenha aumentado em $4 \%$ durante o ano 2000. Esse baixo rendimento ocorre em virtude da relação entre o alto consumo de energia registrado e o baixo volume de água aplicado, sendo que o sistema era acionado para aplicar apenas parte do volume de água que é capaz de bombear.

Os índices médios anuais de consumo de energia para o perímetro foram $0,4773 \mathrm{e} 0,4701 \mathrm{kWh} \mathrm{m}^{-3}$ para os anos de 1999 e 2000, respectivamente, sendo praticamente constantes durante os anos estudados. Os meses que apresentaram maiores índices mensais foram julho de $1999\left(0,7172 \mathrm{kWh} \mathrm{m}^{-3}\right)$ e dezembro de $2000\left(0,6881 \mathrm{kWh} \mathrm{m}^{-3}\right)$. Esses altos índices mensais são devidos à relação entre o alto consumo registrado e o pequeno volume de água aplicado nos lotes.

Segundo Lima et al. (1999), o índice de consumo de energia para o método de irrigação por aspersão convencional, com eficiência de irrigação variando de 60 a $85 \%$, é de 0,2 a $0,6 \mathrm{kWh}$ $\mathrm{m}^{-3}$, respectivamente, e para o método de irrigação por microaspersão, com eficiência de irrigação variando de 80 a 95\%, é de
0,1 a $0,4 \mathrm{kWh} \mathrm{m}^{-3}$, respectivamente. Confrontando-se esses índices com os resultados obtidos, nota-se que os índices de consumo de energia encontrados foram significativamente maiores e uma das explicações é que o sistema era acionado para aplicar apenas parte do volume de água que é capaz de bombear.

\section{Consumo de energia}

A Tabela 4 apresenta os valores mensais de energia consumida, estimada, em excesso e em déficit, para o perímetro, durante os anos estudados.

As necessidades de energia estimadas para o perímetro, correspondentes aos anos de 1999 e 2000 foram de 2.174,4 e 2.112,5 MWh, respectivamente, perfazendo o consumo por unidade de área de $4.829 \mathrm{kWh} \mathrm{ha}^{-1}$ e $3.973 \mathrm{kWh} \mathrm{ha}^{-1}$, respectivamente. Observa-se, no consumo por unidade de área, decréscimo anual de $18 \%$. Esta redução se deve à diminuição no volume de água, simulado para condições de manejo de irrigação adequado, no ano de 2000, em relação ao ano de 1999.

Tabela 4. Energia consumida, estimada, em excesso e déficit para todo o Perímetro Irrigado de Pirapora, MG, durante os anos de 1999 e 2000

\begin{tabular}{|c|c|c|c|c|c|c|c|c|c|c|c|c|c|}
\hline & \multicolumn{13}{|c|}{ Energia Elétrica (MWh) } \\
\hline & Jan & $\mathrm{Fev}$ & Mar & Abr & Mai & Jun & Jul & Ago & Set & Out & Nov & Dez & Total \\
\hline \multicolumn{14}{|c|}{1999} \\
\hline Estimada & 152,1 & 138,8 & 132,3 & 221,2 & 239,6 & 219,5 & 242,0 & 279,4 & 276,1 & 174,3 & 24,8 & 74,0 & $2.174,4$ \\
\hline Excesso & 0,0 & 0,0 & 203,2 & 0,0 & 226,9 & 178,1 & 531,3 & 145,8 & 103,8 & 353,2 & 339,2 & 26,5 & $2.108,0$ \\
\hline Déficit & 137,9 & 1,0 & 0,0 & 44,7 & 0,0 & 0,0 & 0,0 & 0,0 & 0,0 & 0,0 & 0,0 & 0,0 & 183,6 \\
\hline Estimada & 119,5 & 136,5 & 176,4 & 219,2 & 232,4 & 214,4 & 193,9 & 224,1 & 217,4 & 200,1 & 90,5 & 88,1 & $2.112,5$ \\
\hline Excesso & 0,0 & 0,0 & 0,0 & 22,1 & 143,6 & 304,1 & 286,3 & 197,0 & 279,4 & 80,1 & 465,9 & 78,2 & $1.856,8$ \\
\hline Déficit & 115,9 & 25,6 & 104,1 & 0,0 & 0,0 & 0,0 & 0,0 & 0,0 & 0,0 & 0,0 & 0,0 & 0,0 & 245,5 \\
\hline
\end{tabular}


Os excessos de energia anual para o perímetro, durante os anos de 1999 e 2000 , foram de 2.108 e $1.856,8 \mathrm{MWh}$, respectivamente, conduzindo a um desperdício de energia de 97 e $88 \%$, respectivamente. Este desperdício é influenciado, sobretudo, pela falta de um manejo adequado da irrigação pois, segundo estudo realizado pela Companhia Energética de Minas Gerais-CEMIG, citado por Lima et al. (1999), se a irrigação fosse utilizada de forma racional, aproximadamente $20 \%$ da água e $30 \%$ da energia consumidas seriam economizados, sendo $20 \%$ da energia economizada referente à aplicação desnecessária de água e $10 \%$ ao redimensionamento e otimização dos equipamentos utilizados na irrigação.

Confrontando-se, mensalmente, os volumes de água deficitários (Tabela 1) com o consumo deficitário mensal de energia, observa-se que, nos meses de fevereiro e abril de 1999, e abril de 2000, os resultados não seguem a mesma tendência em termos de déficit. Tal fato pode ser justificado em razão da ocorrência do maior tempo de funcionamento do sistema de bombeamento da captação em relação ao sistema booster, sendo que este último contabiliza o volume de água consumido e é utilizado para o cálculo do índice mensal do consumo de energia. Outra justificativa é que o sistema é acionado para aplicar apenas parte do volume de água que é capaz de bombear.

\section{CONCLUSÕES}

1. A estação de bombeamento booster apresentou os mais baixos rendimentos, principalmente nos meses de janeiro.

2. Em razão da aplicação excessiva de água, também foi excessivo o consumo de energia elétrica sendo necessária, portanto, a implantação de um programa de manejo de irrigação visando otimizar o uso de água e de energia elétrica.

\section{LITERATURA CITADA}

Lima, J.E.F.W.; Ferreira, R.S.A.; Christofidis, D. Uso da irrigação no Brasil. O estado das águas no Brasil. Agência Nacional de Energia Elétrica. CD-ROM, 1999.

Lima, J.E.F.W.; Ferreira, R.S.A.; Christofidis, D. Estudo do uso da água e energia elétrica para irrigação no Brasil. http://www.iica.org.uy/p2-5htm. 21 de Abril de 2002.

Medeiros, S.S.; Soares, A.A.; Ramos, M.M.; Mantovani, E.C.; Souza, J.A.A. Avaliação do manejo de irrigação no Perímetro Irrigado de Pirapora, MG. Revista Brasileira de Engenharia Agrícola e Ambiental. Campina Grande, v.7, n.1, p.80-84, 2003. 